\title{
Learning Curve in Cryoballoon Ablation of Atrial Fibrillation - Eight-Year Experience -
}

Maciej Wójcik, MD; Alexander Berkowitsch, PhD; Harald Greis, MD; Sergey Zaltsberg, MD; Christian W. Hamm, MD; Heinz F. Pitschner, MD; Malte Kuniss, MD; Thomas Neumann, MD

\begin{abstract}
Background: We analyzed the procedural experience cryoballoon ablation (CBA) of atrial fibrillation (AF) gained over 8 years in a high-volume centre to understand the influence of the learning curve on feasibility, safety and clinical outcome.
\end{abstract}

Methods and Results: In 424 patients (62\% male) with drug-refractory AF, CBA was performed between 2005 and 2012. The analyzed period was divided into 8 calendar years. The endpoint of the study was arrhythmia recurrence after the 3-month blanking period in the 1-year follow-up since the index procedure, in the absence of anti-arrhythmic drugs class I and III. A combined AF type, Left Atrium size, Renal insufficiency, MEtabolic syndrome, cardiomyopathy (ALARMEc) risk score was calculated for each patient. The overall 1-year success rate of a single CBA was $73 \%$. Continuous increase in 1-year success rate was observed with successive years of the study. The gradual improvement in outcome was related to gradual fall in ALARMEc risk score in successive patients. A continuous decrease in fluoroscopy and procedure time was observed in each subsequent year.

Conclusions: CBA, followed by the proper selection of patients, facilitates a satisfactory outcome, especially in patients at an early stage of PV-trigger-dependent AF. Still, as with each new technology, it requires completion of a learning curve. (Circ $J$ 2014; 78: 1612-1618)

Key Words: Atrial fibrillation; Cryoballoon ablation; Learning curve

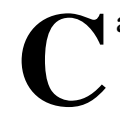
atheter ablation has become an important therapeutic modality for patients with atrial fibrillation (AF). ${ }^{1}$ The number of catheter ablations for AF continues to increase around the world. ${ }^{2}$ With the wider introduction of this procedure into less experienced centers, efforts have been made to assist operators in terms of learning the technique, reducing procedural and fluoroscopy times, minimizing the risk and achieving desired results. ${ }^{3}$ The time-consuming, point-by-point radiofrequency $(\mathrm{RF})$ ablation technique was challenged by the use of novel technologies with a "single-shot" approach to facilitate and speed up the invasive procedure. ${ }^{4}$

Balloon catheters combined with cryothermal energy were superior to anti-arrhythmic therapy and had a similar success rate to RF-based procedures in patients with paroxysmal $\mathrm{AF}$ (PAF). ${ }^{5,6}$ Given that the cornerstone of cryoballoon ablation (CBA) is pulmonary vein isolation (PVI), the technology is intended for patients at an early stage of AF, that is, preferable PV-trigger-dependent AF within normal-sized left atrium (LA).
Operating with a relatively big balloon catheter within a notenlarged LA, and obtaining satisfactory occlusion and catheter adherence in a varying PV anatomy can be laborious. Consequently, even experienced operators in high-volume centers face the learning curve for adopting to the new technology.7,8 For novice and non-experienced operators this could be an even more challenging time.

We analyzed the procedural experience gained over 8 years in a high-volume centre to understand the influence of the learning curve on feasibility, safety and clinical outcome.

\section{Patients}

Between 2005 and 2012 we enrolled 424 consecutive patients with symptomatic and drug-refractory AF. Arrhythmia was documented on electrocardiography (ECG) at least once within the last 3 months before ablation. Exclusion criteria were

Received October 10, 2013; revised manuscript received March 16, 2014; accepted April 2, 2014; released online May 19, 2014 Time for primary review: 18 days

Department of Cardiology, Kerckhoff Heart and Thorax Center, Bad Nauheim (M.W., A.B., H.G., S.Z., C.W.H., H.F.P., M.K., T.N.); Department of Cardiology, Justus-Liebig University of Giessen, Giessen (C.W.H., T.N.), Germany; and Department of Cardiology, Medical University of Lublin, Lublin (M.W.), Poland

Mailing address: Professor Thomas Neumann, MD, Department of Cardiology, Kerckhoff Heart and Thorax Center, Benekestr. 2-8, 61231 Bad Nauheim, Germany. E-mail: t.neumann@kerckhoff-klinik.de

ISSN-1346-9843 doi:10.1253/circj.CJ-13-1253

All rights are reserved to the Japanese Circulation Society. For permissions, please e-mail: cj@j-circ.or.jp 
defined as advanced structural heart disease, including moderate-severe valvular stenosis or insufficiency, previous myocardial infarction, congenital heart disease, left ventricular ejection fraction $<50 \%$, coronary artery bypass graft surgery within the last 3 months, chronic obstructive pulmonary disease treated with $\beta$-sympathomimetic drugs, severe respiratory insufficiency, known bleeding diathesis or intolerance of heparin or oral anticoagulation, attempted AF ablation in the past, LA thrombus, pregnancy, and severe comorbidity.

\section{Pre-Ablation}

Medical history was obtained during ambulatory visits with a thorough review of the medical records including ECG and Holter ECG recordings showing episodes of AF. The risk of procedure was discussed in detail and all patients gave written informed consent. The study was approved by the local institutional ethics committee. Three days before intervention, vitamin $\mathrm{K}$ antagonist was stopped and replaced by subcutaneous low-molecular-weight heparin. Anti-arrhythmic drugs (AAD) were discontinued at least 3 days before ablation. Beta-blockers were allowed according to the protocol.

Previously described, the normalized LA area (NLA) ${ }^{9}$ and Atrial fibrillation type, Left Atrium size, Renal insufficiency, MEtabolic syndrome, cardiomyopathy (ALARMEc) combined risk score was calculated for each individual patient. ${ }^{10,11}$ Enlarged LA was defined as NLA $\geq 11.5 \mathrm{~cm}^{2} / \mathrm{m}^{2}$.

\section{Intervention}

The procedure has been described previously. ${ }^{12,13}$ Briefly, we used 23- and/or 28-mm CB (ArcticFront ${ }^{\mathrm{TM}}$ until April 2012 and Arctic FrontAdvanced ${ }^{\mathrm{TM}}$ since May 2012, MedtronicCryocath). The single application time was 240-300 s per freeze. During CBA of the right-sided PV, unaffected phrenic movement was monitored by both continuous phrenic nerve (PN) stimulation and continuous monitoring of spontaneous breathing. The observation period after initial isolation to check for recurrence of PV conduction was $30 \mathrm{~min}$. If a PV could not be isolated with a first-choice CB size, we used a second (different sized) one. The isolation was verified as complete elimination of all PV signals at the antral or ostial level. Additionally, exit and entrance-block of all veins was confirmed on pacing maneuvers, as previously described.12,13

\section{Post-Ablation Management}

Oral anticoagulation was continued, for at least 3 months, targeting an international normalized ratio of 2-3. All patients had echocardiography and chest X-ray to document phrenic movement and to exclude pericardial effusion and PN palsy (PNP). Treatment with AAD class I and class III was stopped.

\section{Follow-up}

The strict follow-up protocol fulfils the latest recommendations. ${ }^{1}$ After discharge from hospital, patients were scheduled for quarterly follow-up visits. Late follow-up ( $>1$ year after intervention) was performed once per year. Seven-day Holter ECG recordings were obtained at each follow-up visit. Each patient, in the case of any palpitations, was instructed to have ECG performed for confirming or excluding AF, atrial flutter or atrial tachycardia (AFLAT). Beta-blockers were allowed in the follow-up.

\section{Statistical Analysis}

The study was designed as an observational cohort study. The analyzed period was divided into 8 calendar years (2005-2012) to include patients who underwent CBA within each of fol-

\begin{tabular}{|lc|}
\hline \multicolumn{2}{|l|}{ Table 1. Baseline Patient Characteristics $(\mathbf{n}=\mathbf{4 2 4})$} \\
Male & \\
Age (years) & $266(62.33)$ \\
PAF & $58(49-65)$ \\
History of AF (years) & $322(85.38)$ \\
BMI (kg/m $\left.{ }^{2}\right)$ & $5.20(2.12-9.99)$ \\
Echocardiography & $26.72(24.51-29.61)$ \\
LA short axis (mm) & \\
LA long axis (mm) & $38(36-40)$ \\
LAA (cm $\left.{ }^{2}\right)$ & $51(47-55)$ \\
Normalized LAA (cm $\left.{ }^{2} / \mathrm{m}^{2}\right)$ & $19.24(17.28-22)$ \\
LVEF (\%) & $9.53(8.43-10.76)$ \\
Medical history & $62(57-62)$ \\
GFR (ml/min) & \\
Hypertension & $92.42(80.35-106.58)$ \\
CAD & $249(58.73)$ \\
Diabetes mellitus & $25(5.89)$ \\
Metabolic syndrome & $25(5.89)$ \\
AAD at inclusion & $145(33.69)$ \\
Class I & \\
Class II & $159(37.5)$ \\
Class III & $290(65.4)$ \\
Amiodarone & $94(22.17)$ \\
Dronedaron & $41(9.67)$ \\
Sotalol & $31(7.31)$ \\
\hline
\end{tabular}

Data given as $n(\%)$ or median (IQR).

$A A D$, anti-arrhythmic drug; $A F$, atrial fibrillation; $B M I$, body mass index; $C A D$, coronary artery disease; GFR, glomerular filtration rate; LA, left atrium; LAA, left atrium area; LVEF, left ventricular ejection fraction; PAF, paroxysmal atrial fibrillation.

lowing years. The endpoint of the study was the first AFLAT recurrence after the 3-month blanking period in the 1-year follow-up since the index procedure, in the absence of AAD (class I and III) therapy. Kaplan-Meier univariate analysis was used to estimate AFLAT-free survival. Continuous data are described as median, lowest (IQR25) and highest (IQR75) quartiles. The discrete variables are given as number and percentage. The differences between variables were analyzed using chi-squared test, Kruskal-Wallis test, and multivariate regression analysis, where appropriate. The differences were considered significant for $\mathrm{P}<0.05$.

\section{Results}

\section{Patients}

In total, 424 consecutive patients were treated with circumferential antral (28-mm CB) or ostial (23-mm CB) PVI using a $\mathrm{CB}$ catheter. A new-generation CB (Arctic FrontAdvanced ${ }^{\mathrm{TM}}$ ) was used in 75 patients (16\%; only $28-\mathrm{mm}$ balloons). Clinical characteristics are given in Table $\mathbf{1}$.

\section{Procedural Characteristics}

Acute PVI was achieved in 324 patients (76.4\%) with a $28-\mathrm{mm} \mathrm{CB}$ and in $50(11.8 \%)$ with a 23-mm CB only. A combination of both $23-\mathrm{mm}$ and $28-\mathrm{mm} \mathrm{CB}$ was used in 50 patients $(11.8 \%)$.

Atypical PV anatomy was found in 34 patients $(8.2 \%)$ as follows: only additional PV in 12 patients $(2.8 \%)$, only common PV ostium in 22 patients $(5.2 \%)$ and both additional PV 


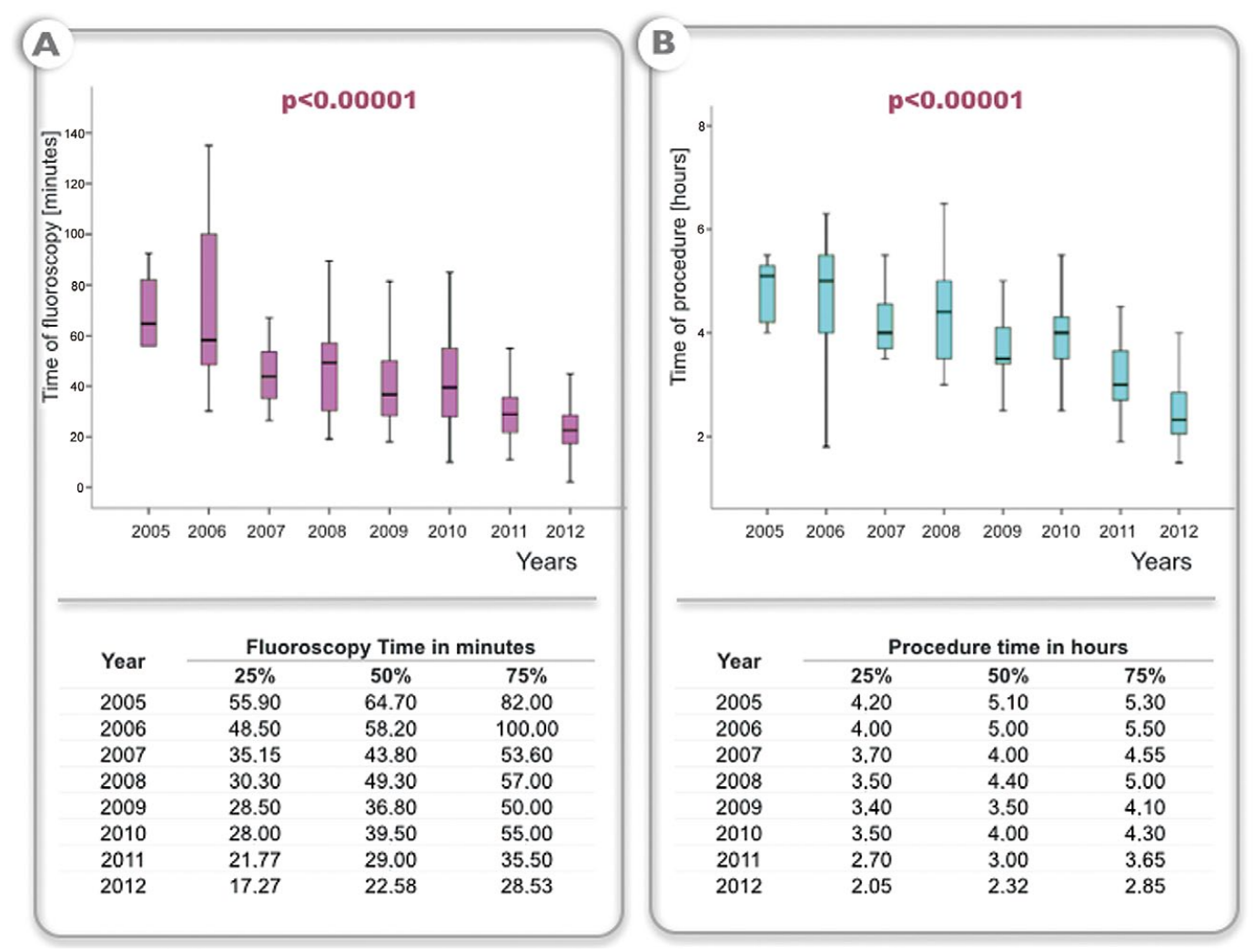

Figure 1. Change in (A) fluoroscopy and (B) procedure time in consecutive years.

and common ostium in 19 patients (4.5\%). Isolation of all PV was achieved, using different balloon sizes, if needed.

A continuous decrease in fluoroscopy time (Figure 1A) and procedure time (Figure 1B) was observed in each subsequent year $(\mathrm{P}<0.00001)$. Moreover, both fluoroscopy time and procedure time were significantly shorter in patients with lower ALARMEc risk score $(\mathrm{P}=0.001$ and $\mathrm{P}=0.005$, respectively; Figure 2).

On univariate analysis there was a significant association between fluoroscopy time and ALARMEC $(\mathrm{P}<0.001)$. On multivariate analysis, year of procedure was an independent predictor of reduced procedure time, and both year of procedure (Figure 1) and ALARMEc risk score (Figure 2) were independent predictors of fluoroscopy time.

\section{Complications}

Incidence of complications is listed in Table 2. We did not find any significant decrease in complication rate over the 8-year period. The increased number of observed PNP in 2012 was related to the introduction of a new Arctic FrontAdvanced ${ }^{\mathrm{TM}}$ CB. Still, no significant difference in the incidence of PNP between patients treated with first-generation and secondgeneration $\mathrm{CB}$ was observed.

We did, however, note an increase in PNP associated with first experience with second-generation balloons (12\%, 9/75 vs. $4.8 \%, 17 / 349)$.

We noted that PNP occurred significantly more frequently in patients with enlarged LA as compared to the others: $15 \%$ $(22 / 144)$ vs. $6 \%(18 / 280)$, respectively $(\mathrm{P}=0.005)$. None of the studied patients developed any clinical symptoms in terms of possible esophageal lesions; no atrioesophageal fistula occurred.

\section{Follow-up}

None of the 424 patients was lost in the observational period. The 1-year success rate increased significantly in each subsequent year (Figure 3A, $\mathrm{P}=0.025$ ). The gradual improvement in outcome was related to gradual fall in ALARMEc risk score (Figure 3B, P=0.0001) in successive patients. The overall 1-year success rate of single CBA was $73 \%$.

\section{Discussion}

The combination of a theoretically safer cryothermal energy source with the ease of use associated with balloon-based catheter ablation systems has positioned the expandable cryoablation balloon catheter technique at the forefront of promising new technologies. ${ }^{14}$

In this retrospective observational study we analyzed the influence of the learning curve on the feasibility, safety and 1-year clinical outcome after single CBA. The present data reflect the experience with CBA gained over 8 years in a highvolume centre. We noted that the gradually increasing improvement in 1-year outcome was related to better pre-procedural selection of patients and not to operator experience per se. This gradual improvement in experience was reflected in continuous decrease in fluoroscopy and procedure times observed in consecutive years. 


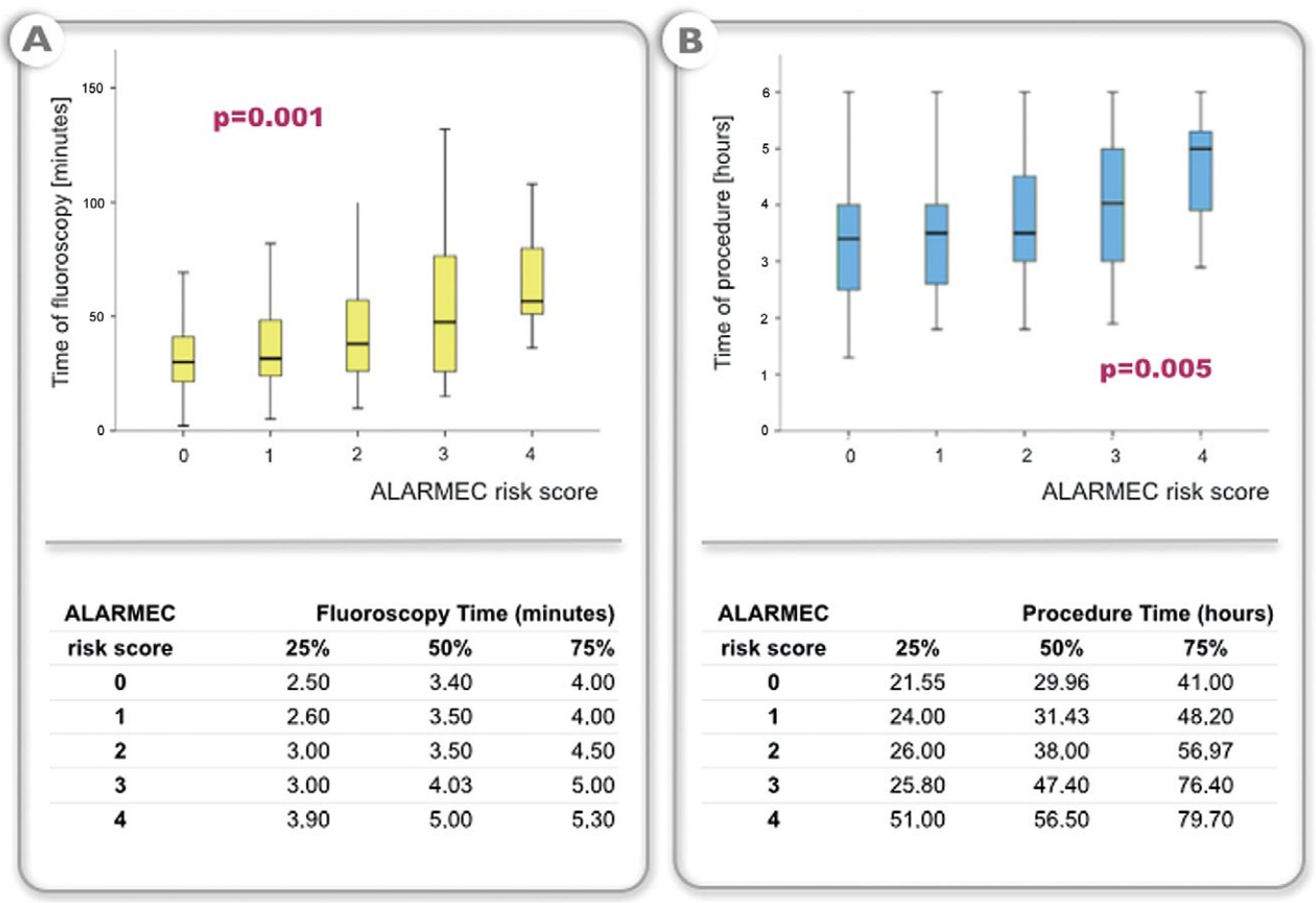

Figure 2. (A) Fluoroscopy and (B) procedure time vs. atrial fibrillation type, Left Atrium size, Renal insufficiency, Metabolic syndrome, cardiomyopathy (ALARMEc) risk score.

\begin{tabular}{|c|c|c|c|c|c|}
\hline Complications per year & $\begin{array}{c}\text { Vascular } \\
\text { complications } \\
\text { n (\%) }\end{array}$ & $\begin{array}{c}\text { Cardiac } \\
\text { tamponade } \\
\mathrm{n}(\%)\end{array}$ & $\begin{array}{c}\text { Pericardial } \\
\text { effusion } \\
\text { n (\%) }\end{array}$ & $\begin{array}{l}\text { PNP } \\
\text { n (\%) }\end{array}$ & $\begin{array}{c}\text { All complications } \\
\text { n (\%) }\end{array}$ \\
\hline $2005, n=14$ & 0 & 0 & $1(7.14)$ & $1(7.14)$ & $2(14.28)$ \\
\hline $2006, n=52$ & $1(1.92)$ & $1(1.92)$ & $2(3.84)$ & $3(5.77)$ & $7(13.46)$ \\
\hline $2007, n=24$ & $1(4.17)$ & 0 & 0 & 0 & $1(4.17)$ \\
\hline $2008, n=25$ & 0 & 0 & 0 & $2(8.00)$ & $2(8.00)$ \\
\hline 2009, $n=69$ & 0 & $1(1.45)$ & 0 & $3(4.35)$ & $4(5.80)$ \\
\hline $2010, n=53$ & 0 & $1(1.89)$ & $1(1.89)$ & $2(3.77)$ & $4(7.55)$ \\
\hline $2011, n=70$ & 0 & 0 & 0 & $4(5.71)$ & $4(5.71)$ \\
\hline $2012, n=117$ & 0 & 0 & 0 & $11(9.40)$ & $11(9.40)$ \\
\hline $\mathrm{CB}, \mathrm{n}=42$ & 0 & 0 & 0 & $2(4.76)$ & $2(4.76)$ \\
\hline CBA, $n=75$ & 0 & 0 & 0 & $9(12.00)$ & $9(12.00)$ \\
\hline All, $n=424$ & $2(0.47)$ & $3(0.71)$ & $4(0.94)$ & $26(6.13)$ & $35(8.25)$ \\
\hline
\end{tabular}

$\mathrm{CB}$, cryoballoon; CBA, cryoballoon ablation; PNP, phrenic nerve palsy.

\section{Procedural and Fluoroscopy Times}

New technology always takes time to be adopted. Even highly experienced operators are more cautious during first procedures. Familiarization with the new technology (eg, bidirectional catheter, ${ }^{15}$ steerable sheath ${ }^{3}$ or remote robotic ablation ${ }^{16,17}$ ) is combined with prolonged procedural and fluoroscopy times. ${ }^{3,15-18}$

Cryoballoon technology combines both a big (14-F) steerable sheath and a sophisticated catheter. Both tools are different from those used for RF ablation. Learning how to handle both, maneuver within the LA, avoid air emboli, safely inflate a $\mathrm{CB}$, properly wedge it in the ostium/antrum of a PV, check the quality of its position with a contrast agent, monitor against PNP, abruptly stop energy application in case of PNP and, finally, safely remove the catheter from the LA, needs training. Such training prolongs first procedures, and the additional attention needed to achieve the best PV occlusion and avoid CBrelated complications prolongs fluoroscopy time. Centers with extensive experience in CBA reported a progressive decrease in procedural and fluoroscopy time with increasing operator familiarity. ${ }^{14}$ Indeed, we noted a significant reduction, more than by half, both in procedural and fluoroscopy time. Similar results were reported in 3, recently published, studies..$^{7,8,19}$ The 

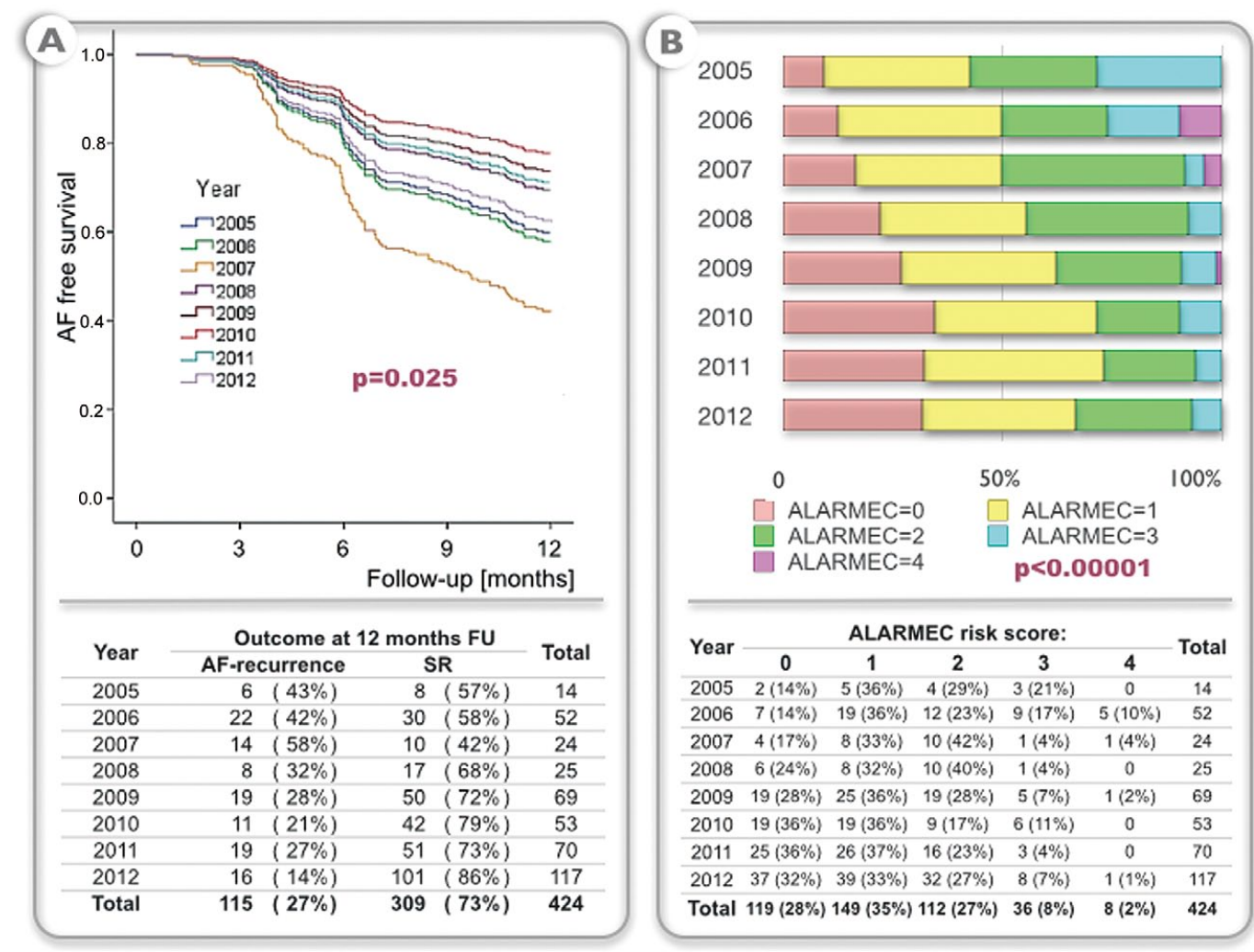

Figure 3. (A) The gradual improvement in 1-year atrial fibrillation (AF)-free survival in each subsequent year was associated with (B) the gradual fall in Atrial fibrillation type, Left Atrium size, Renal insufficiency, Metabolic syndrome, cardiomyopathy (ALARMEc) risk score in successive patients in consecutive years.

STOP-AF investigators randomized 163 patients in 26 centers for $\mathrm{CB}$, that is, approximately 6 patients/center. ${ }^{8}$ Consequently, they reported long procedure and fluoroscopy exposure times (371 and $63 \mathrm{~min}$, respectively), characteristic of an early stage in the learning curve. .,20 $^{2}$

\section{Outcome}

The cornerstone of CBA is PVI at the antral (28-mm CB) and ostial (23-mm CB) levels. In comparable studies, reporting a 3-month blanking period, the 1-year freedom from AF recurrence was $73 \%$ and $45 \%$ in patients with paroxysmal and persistent $\mathrm{AF}$, respectively. ${ }^{14} \mathrm{CBA}$, which eliminates triggers and, partially, the substrate located near the LA-PV junction, results in a high success rate in PAF patients. ${ }^{7,12-14}$ Failure of PVI in this group is rather a result of incomplete isolation of LA-PV triggers or existing, but not identified, non-LA-PV triggers. In patients with non-PAF, enlarged LA, impaired renal function, that is, with more advanced anatomic and electrical changes within the LA, sole circumferential PVI is rarely sufficient to eliminate $\mathrm{AF}$ and the overall outcome is low. ${ }^{12,14}$ Consequently, adequate selection of patients for CBA seems to be crucial. Indeed, we observed an increase in the success rate (from 59\%, $79 / 134$ in 2005-2008 up to 76\%, 251/329 in 2009-2012), which was related to the better understanding of AF pathophysiology followed by more rigorous selection of patients (expressed as increased number of patients with lower ALARMEc risk score in subsequent years; Figure 2) and not to better operator experience per se.
We used ArcticFrontAdvance ${ }^{\mathrm{TM}} \mathrm{CB}$ in $18 \%$ of the present subjects in 2012 only.

\section{Complications}

The complications of RF ablation have been widely recognized. ${ }^{1}$ Introduction of a new method of AF ablation, such as CBA, can entail a risk of complications exclusively related to this method. With regard to experienced operators, already familiar with current technology, the patients are mostly at risk of new and not widely reported complications related to the new method. For inexperienced operators each complication falls into their learning curve. Moreover, vascular complications cannot be completely avoided. Bai et al noted that lowervolume centers experienced a higher complication rate during the first cases. ${ }^{17}$ Similarly, Ellis et al observed that the highestvolume hospitals had the lowest rate of overall complications, while the lowest-volume hospitals had the highest rate of overall complications. ${ }^{21} \mathrm{With}$ the increase in the number of procedures performed per year, the annual probability of in-hospital complication increased significantly, driven mainly by the occurrence of vascular access complications and cardiac perforation/tamponade. ${ }^{21}$

The incidence of major complications, such as pericardial effusion/tamponade requiring intervention $(0.7 \%)$ and vascular complications $(0.4 \%)$ was similar to previously published data. ${ }^{14}$ We noted periprocedural PNP in $6 \%$ of cases, that is, similar to previously reported data. ${ }^{14}$ Introduction of the ArcticFrontAdvance ${ }^{\mathrm{TM}} \mathrm{CB}$ in 2012 resulted in 9 patients with 
PNP. Still, in all of the present patients, full recovery from PNP, between some minutes after cessation of cryoenergy application and up to 1 year after CBA, was observed. Nevertheless, despite different approaches proposed recently on the avoidance of PNP (preprocedural imaging of the RSPV-SVC relationship, avoidance of antral catheter position, close monitoring of temperature and abrupt cessation of energy delivery, ${ }^{22}$ immediate balloon deflation ${ }^{23}$ and monitoring of the amplitude of the diaphragmatic compound motor action potentials ${ }^{24}$ ), the problem of PNP has not been eliminated. ${ }^{22}$

Moreover, a significantly higher number of PNP was observed in patients with enlarged LA, with NLA being a predictor of PNP. We assume that it could be associated with the changed anatomical course of PN and/or the shortened distance between $\mathrm{PN}$ and a CB, being pushed towards the PV for optimal occlusion, in individuals with enlarged LA.

The incidence of complications was not significantly decreased during the learning curve. We believe that this reflects the fact that all operators were highly experienced both in standard and advanced ablation procedures. Moreover, the high number of PNP in 2012 was possibly related to the introduction of a second-generation $\mathrm{CB}$. A higher risk of PNP during CBA with ArcticFrontAdvance ${ }^{\mathrm{TM}}$ has been already reported.

Still, we cannot exclude the possibility that the learning curve, in the case of low-volume centers and inexperienced operators, might significantly influence complication rate.

\section{Clinical Implications}

The clinical implications of the present results are substantial with regard to the care of patients with AF indicated for CBA. First, patient selection is crucial. Patients with lower ALARMEc risk score appear to be the first-line candidates for CBA. Second, longer procedural time and exposure to fluoroscopy could be expected in centers at an early stage of the learning curve and in patients with atypical PV anatomy. Third, patients should be aware of possible procedure-related complications, including PNP, even in highly experienced laboratories. Further preprocedural imaging and more intense monitoring of PN function could minimize the risk of PNP. Finally, ongoing surveillance is warranted, even if CBA was deemed initially successful. Incidence of late recurrence may be related to the extent of ECG monitoring, and earlier recurrence may be missed in selected patients with no or minimal symptoms. ${ }^{1,25}$

\section{Study Limitations}

This study has the following limitations. First, this was a singlecenter, observational cohort report with the inherent limitations of that study design. There was, however, no selection bias for study because since all consecutive patients undergoing CBA were included for analysis. Second, the present data reflect the experience of CB gained during 424 procedures over 8 years in a high-volume centre by operators already experienced in standard and advanced ablation procedures. The learning curve in low-volume centers and for inexperienced operators might differ significantly. Third, in the majority of cases we performed double transseptal puncture. Currently used, a single transseptal access with Achieve ${ }^{\mathrm{TM}}$ Mapping Catheter, could further decrease procedural and fluoroscopy time. Fourth, in the last year new approaches, unknown at the time of inclusion for the study, have been proposed to avoid PNP. We monitored PN function by continuous PN stimulation and continuous monitoring of spontaneous breathing. And fifth, none of the present patients developed PV stenosis. Still, the possibility of such a complication should not be neglected during the learning curve.

\section{Conclusions}

The aim of CBA is PVI. The present results show that this technology allows achievement of satisfactory outcome, especially in patients in the early stage of PV-trigger-dependent AF, with an acceptable complication rate. Still, as with each new technology, it requires completion of a learning curve. In centers with operators already experienced in other ablation techniques, a significant decrease in procedural and fluoroscopy time could be expected with increased experience with CB technology. A higher success rate could be expected in selected patients with low ALARMEc risk score, that is individuals with AF dependent on PV triggers and not a substrate within LA. Consequently, the proper selection of patients is vital for the success of CBA of AF.

Focusing on patients with typical PV anatomy could reduce the need for the use of additional catheters and further shorten the learning curve.

Complications, especially PNP, could not be avoided even with increased operator experience. Still, with thorough periprocedural PN monitoring, PNP was a transient complication. Other serious complication with the need for intervention were relatively rare.

\section{Acknowledgments}

Dr Maciej Wójcik was supported by European Heart Rhythm Association (2-year Clinical Electrophysiology Fellowship, 2007-2009); Professor Thomas Neumann has received speakers' honoraria from MedtronicCryocath; Dr Malte Kuniss has received speakers' honoraria and honoraria for advisory board meetings from MedtronicCryocath; Dr Heinz-Friedrich Pitschner has received honoraria for advisory board meetings from MedtronicCryocath.

\section{Funding Sources}

None.

\section{References}

1. Calkins H, Kuck KH, Cappato R, Brugada J, Camm AJ, Chen SA, et al. 2012 HRS/EHRA/ECAS expert consensus statement on catheter and surgical ablation of atrial fibrillation: Recommendations for patient selection, procedural techniques, patient management and follow-up, definitions, endpoints, and research trial design. Europace 2012; 14: 528-606.

2. Cappato R, Calkins H, Chen SA, Davies W, Iesaka Y, Kalman J, et al. Updated worldwide survey on the methods, efficacy, and safety of catheter ablation for human atrial fibrillation. Circ Arrhythm Electrophysiol 2010; 3: 32-38.

3. Rajappan K, Baker V, Richmond L, Kistler PM, Thomas G, Redpath $\mathrm{C}$, et al. A randomized trial to compare atrial fibrillation ablation using a steerable vs. a non-steerable sheath. Europace 2009; 11: $571-575$.

4. Ernst S. Cryo balloon pulmonary vein isolation: Is it really all so "simple"? J Am Coll Cardiol 2013; 61: 1724-1725.

5. Linhart M, Bellmann B, Mittmann-Braun E, Schrickel JW, Bitzen A, Andrie R, et al. Comparison of cryoballoon and radiofrequency ablation of pulmonary veins in 40 patients with paroxysmal atrial fibrillation: A case-control study. J Cardiovasc Electrophysiol 2009; 20: $1343-1348$.

6. Kojodjojo P, O’Neill MD, Lim PB, Malcolm-Lawes L, Whinnett ZI, Salukhe TV, et al. Pulmonary venous isolation by antral ablation with a large cryoballoon for treatment of paroxysmal and persistent atrial fibrillation: Medium-term outcomes and non-randomised comparison with pulmonary venous isolation by radiofrequency ablation. Heart 2010; 96: 1379-1384.

7. Vogt J, Heintze J, Gutleben KJ, Muntean B, Horstkotte D, Nolker G. Long-term outcomes after cryoballoon pulmonary vein isolation: Results from a prospective study in 605 patients. J Am Coll Cardiol 2013; 61: $1707-1712$.

8. Packer DL, Kowal RC, Wheelan KR, Irwin JM, Champagne J, Guerra PG, et al. Cryoballoon ablation of pulmonary veins for paroxysmal atrial fibrillation: First results of the North American Arctic Front (STOP AF) pivotal trial. J Am Coll Cardiol 2013; 61: 1713 - 
1723.

9. Berkowitsch A, Neumann T, Kuniss M, Janin S, Wojcik M, Zaltsberg $\mathrm{S}$, et al. Therapy with renin-angiotensin system blockers after pulmonary vein isolation in patients with atrial fibrillation: Who is a responder? Pacing Clin Electrophysiol 2010; 33: 1101-1111.

10. Berkowitsch A, Kuniss M, Greiss H, Wojcik M, Zaltsberg S, Lehinant $\mathrm{S}$, et al. Impact of impaired renal function and metabolic syndrome on the recurrence of atrial fibrillation after catheter ablation: A long term follow-up. Pacing Clin Electrophysiol 2012; 35: 532-543.

11. Wojcik M, Berkowitsch A, Greiss H, Zaltsberg S, Pajitnev D, Deubner $\mathrm{N}$, et al. Repeated catheter ablation of atrial fibrillation: How to predict outcome? Circ J 2013; 77: 2271-2279.

12. Neumann T, Vogt J, Schumacher B, Dorszewski A, Kuniss M, Neuser $\mathrm{H}$, et al. Circumferential pulmonary vein isolation with the cryoballoon technique: Results from a prospective 3-center study. J Am Coll Cardiol 2008; 52: 273-278.

13. Neumann T, Wojcik M, Berkowitsch A, Erkapic D, Zaltsberg S, Greiss H, et al. Cryoballoon ablation of paroxysmal atrial fibrillation: 5 -year outcome after single procedure and predictors of success. Europace 2013; 15: 1143-1149.

14. Andrade JG, Khairy P, Guerra PG, Deyell MW, Rivard L, Macle L, et al. Efficacy and safety of cryoballoon ablation for atrial fibrillation: A systematic review of published studies. Heart Rhythm 2011; 8: $1444-1451$.

15. Mantziari L, Suman-Horduna I, Gujic M, Jones DG, Wong T, Markides V, et al. Use of asymmetric bidirectional catheters with different curvature radius for catheter ablation of cardiac arrhythmias. Pacing Clin Electrophysiol 2013; 36: 757-763.

16. Schmidt B, Tilz RR, Neven K, Julian Chun KR, Furnkranz A, Ouyang F. Remote robotic navigation and electroanatomical mapping for ablation of atrial fibrillation: Considerations for navigation and impact on procedural outcome. Circ Arrhythm Electrophysiol 2009; 2: 120 128.

17. Bai R, Di Biase L, Valderrabano M, Lorgat F, Mlcochova H, Tilz R, et al. Worldwide experience with the robotic navigation system in catheter ablation of atrial fibrillation: Methodology, efficacy and safety. J Cardiovasc Electrophysiol 2012; 23: 820-826.

18. Wojcik M, Erkapic D, Berkowitsch A, Zaltsberg S, Greiss H, Schmitt $\mathrm{J}$, et al. Ipsilateral circumferential radiofrequency ablation of atrial fibrillation with irrigated tip catheter. Circ J 2013; 77: 2280-2287.

19. Van Belle Y, Janse P, Rivero-Ayerza MJ, Thornton AS, Jessurun ER, Theuns D, et al. Pulmonary vein isolation using an occluding cryoballoon for circumferential ablation: Feasibility, complications, and short-term outcome. Eur Heart J 2007; 28: 2231 -2237.

20. Wójcik M, Berkowitsch A, Neumann T. Letter to the editor: Can we STOP AF with cryoballoon ablation? J Am Coll Cardiol 2013; 62: $1305-1306$.

21. Ellis ER, Culler SD, Simon AW, Reynolds MR. Trends in utilization and complications of catheter ablation for atrial fibrillation in medicare beneficiaries. Heart Rhythm 2009; 6: 1267-1273.

22. Kuhne M, Knecht S, Altmann D, Kawel N, Ammann P, Schaer B, et al. Phrenic nerve palsy during ablation of atrial fibrillation using a 28-mm cryoballoon catheter: Predictors and prevention. J Interv Card Electrophysiol 2013; 36: 47-54.

23. Ghosh J, Sepahpour A, Chan K, Singarayar S, McGuire MA. Immediate balloon deflation for prevention of persistent phrenic nerve palsy during pulmonary vein isolation by balloon cryoablation. Heart Rhythm 2013; 10: 646-652.

24. Franceschi F, Dubuc M, Guerra PG, Delisle S, Romeo P, Landry E, et al. Diaphragmatic electromyography during cryoballoon ablation: A novel concept in the prevention of phrenic nerve palsy. Heart Rhythm 2011; 8: 885-891.

25. Verma A, Champagne J, Sapp J, Essebag V, Novak P, Skanes A, et al. Discerning the incidence of symptomatic and asymptomatic episodes of atrial fibrillation before and after catheter ablation (DISCERN $\mathrm{AF})$ : A prospective, multicenter study. JAMA Intern Med 2013; 173: $149-156$. 